\title{
Um dia todos seremos Montag
}

\section{One day we will be Montag}

\author{
Paulo Venturelli*
}

\begin{abstract}
RESUMO
Partindo de conversa comum em que a menção de Guernica causou constrangimento, pois as pessoas não conheciam o quadro, discutimos o caráter educacional especializado, em que os campos gerais do conhecimento não são valorizados. Isto denota falta de leitura que, quando praticada, é mero consumo. A escola tenta desenvolver esta prática, mas erra na concepção do ler e no não atendimento às necessidades do aluno. O professor não cumpre o papel de mediador, nem mostra a leitura como superação de dogmas. É urgente rever a política curricular, presa à cultura hegemônica. Assim, a escola deve abrir-se ao multiculturalismo, revelar a flutuação dos conceitos culturais. Na arte, tem de ensinar como esta não se faz cumprindo regras, mas rompendo-as, ao lado do que, o aluno aprenderá que cultura é crise. Percebendo isso, terá conhecimento de sua subjetividade como processo em construção e cultura como interdependência. Arte não é sagrada. Desmistificando mitos, o aluno está em condições de ser o modelador de sua história, não apenas consumidor de alheias. Verá a angústia como deflagradora de criatividade, impulso à superação de limites. Como a literatura perde espaço na sociedade, torna-se esotérica, recomendamos seu abandono, em nome de outras narrativas que ensinarão a sociedade como trançado de discursos. Sensibilizado e consciente disto, o aluno então pode trabalhar o literário como relação especial entre os discursos sociais.

Palavras-chave: desmistificação, multiculturalismo, leitura não-literária.
\end{abstract}

* Doutor em Literatura Brasileira pela USP. Professor de Literatura Brasileira do DELIN/UFPR. paventur@uol.com.br 


\begin{abstract}
This works starts with the analysis of an uncomfortable situation created, in a occasional speech, by the mention to Guernica, since involved people didn't know the picture. We discuss, here, the character of specialized education, in which general areas of education are not valorized, what reveals reading lack, which when is done it is just for consume. School tries to develop this practice but commit mistakes in relation to its conception of reading and do not understand learners necessities. Teachers do not play the role of mediator, neither present reading as dogma overcoming. It's urgent to review Curriculum policy, which is product of hegemonic culture. In this way, school should open itself for multiculturalism and reveal the cultural concepts fluctuation. In art, it's to teach how it doesn't exist following rules but break that ones, at the same time, learners will learn that culture is crisis. After notice that, learners will know their subjectivity as a building process and culture as interdependence. Art is not sacred. Demystifying myths, the learner is in condition to be builder of his own history and not just a consumer of other ones histories. The learner will see anguish as creativity outbreak and impulse to limits overcome. As literature looses its place in society, it becomes esoteric, and we recommend its abandon, in name of other narratives that will teach society as discourse twisting. Tender-hearted and conscious of that, learner can work then the literary as special relation among the social discourses.
\end{abstract}

Key-words: Demystification, multiculturalism, not-literary reading.

\title{
Cena 1: Puxando o fio da meada
}

Em férias recentes no litoral de Santa Catarina, estávamos num grupo a conversar. A roda era composta por empresário, padre, estudante de administração, outro, de biologia, orientador pedagógico e nós, professores de literatura. As colocações versavam sobre vários assuntos atuais até que, num determinado momento, fizemos menção ao Guernica, de Picasso. O silêncio foi geral. Trocaram-se olhares de constrangimento. Resumo: ninguém sabia do que falávamos.

Podemos considerar que aquele era um grupo seleto e representativo do Brasil classe-média. Afinal, todos ali tinham curso universitário, de quem se espera um mínimo de conhecimento geral. Talvez, ignorar um quadro 
não seja tão grave assim, se não se apresentasse naquele contexto um sintoma do que é a formação educativa-profissional em nosso país. Numa distorção histórica de décadas, cada um procura especializar-se, conhecendo relativamente sua área e tendo olhos fechados para outros campos de produção. Ou seja, numa sociedade obcecada por tecnologias, o que até há alguns anos podia-se chamar de cultura humanística foi abandonada por não ter aplicabilidade prática. E este é o problema principal. Educar passou a ser preparar para o mercado e isto significa: fazer assimilar um arsenal técnico eficiente para exercer determinada função. Pensar de forma crítica, fazendo conexões e chegando a patamares inesperados, burilar a sensibilidade para captar o mundo dentro de novos padrões que questionem os existentes e até proponham sua superação é trabalho de gerações, demanda tempo, e isso contraria as expectativas imediatistas da sociedade.

Neste quadrante, o desconhecimento de Guernica, como um dos ícones fundamentais da pintura do século 20, torna-se sintoma alarmante, levando em conta a formação de todas aquelas pessoas. Mas alguém se pode perguntar: conhecer aquele quadro torna o homem melhor? Talvez, não. Contudo, saber o que é tal pintura, o que representa no momento de sua realização e suas projeções de futuro, certamente fornecem um mapeamento importante de nossa época, auxiliando-nos na localização do tempo e do espaço. Conhecimento que não significa mera acumulação e sim estímulo para se criar pontes entre linguagens, o que leva a um desvelamento mais promissor do mundo que nos rodeia. Ainda mais se pesarmos o fato de que estamos passando por época de mudanças radicais, quando é necessário repertório consistente para que a interpretação do mundo não venha apenas embalada pelo que ditam os meios de comunicação. Como o nome diz, estes são meios com os quais interage nosso conhecimento. Com visão ampla das cercanias histórico-sociais e da produção cultural humana, ao entrar em contato com estes meios, uma pessoa terá condições mais sedimentadas para ser portador de inteligência. Queremos dizer: intus leggere, ser capaz de ler dentro. ${ }^{1} \mathrm{E}$, nenhuma sociedade que se preze pode dispensar a formação de pessoas inteligentes, aquelas que, lendo dentro dos fatos, estão em condição de estabelecer a liga de concatenação entre eles, por mais dispersos que pareçam à primeira vista.

1 LIBÂNIO, C. A. (Frei Betto). Um sentido para a vida. Revista de educação, Salvador, n. 27, p. 13, dez. 1999. CEAP. 
O que sobressai numa conversa como a referida não é apenas um não-saber pontual. Desencava-se da situação um problema de raízes mais fundas: a falta de leitura, tema que abordamos a seguir.

\section{Cena 2: $O$ que é ler?}

Desde os anos 70, a escola no Brasil vem adotando livros, no esforço de ampliar o número de leitores entre nós. Os resultados mostram-se pífios. Para tanto, basta constatar os dados de recente pesquisa publicada pela Folha de São Paulo: para o brasileiro, de um modo geral, leitura e prazer não se associam; dos 6.673 entrevistados, apenas 30\% tinham lido um livro nos três meses anteriores à pesquisa; $14 \%$ declararam que nunca lêem; $11 \%$ não o fazem por falta de recurso financeiro, enquanto apenas $8 \%$ dispõem-se a ir até uma biblioteca para retirar um livro. Agora, significativo é notar que 39\% simplesmente afirmam não ter tempo para ler, sendo que $10 \%$ demonstram dificuldade para a apreensão e o entendimento de frases e palavras. $^{2}$ Entre os que lêem, a literatura não está no topo dos interesses - um dos motivos da proposta que faremos no final desta reflexão.

Está estampado nas cifras o fracasso das batalhas em prol da leitura, fruto da própria concepção do que seja ler. Isto se torna nítido, por sua vez, na visão que impulsiona os trabalhos escolares e comanda as relações com o aluno ou o ser humano em geral. A leitura na escola ou na sociedade vem seguindo trilho de mero consumo, além de ser uma atividade desfibrada, sem ligação com as necessidades vitais do leitor. Quais são estas? Obviamente, a cada aluno correspondem objetivos pessoais diferenciados por sua história de vida. Só por isso, adotar um único livro para toda uma turma, de antemão homogeniza o heterogêneo, nivela as diferenças, desrespeita as sensibilidades e não surte o efeito procurado: a criação de leitores. O livro, em especial a obra que se propõe como literatura, precisa de mediação. Este seria o papel precípuo do professor: tornar-se a ponte, o elo de ligação entre o universo dos livros e o universo dos alunos. Auscultando as necessidades, as diferenças, os intuitos, a armadura sensível ou não

2 BRASILEIRO não encontra prazer na leitura. Folha de São Paulo, 14 jul. 2001. Ilustrada, p. E-8. 
destes em relação às suas circunstâncias, o professor precisa propor leituras que venham ao encontro de carências e expectativas. Por isso, o livro não pode apenas cumprir função escolar. Nosso mundo fragmentado, tenso, multicultural é campo aberto à expressão de variadas nuances. Assim, é urgente que a escola discuta temas que vão das sexualidades à política, do dinheiro ao consumo, das etnias às artes etc., para que as verdades introjetadas como dogmas intocáveis tenham reconstituídas suas histórias e possam ocupar seu lugar real no horizonte das novas gerações como apenas mais um discurso na malha constitutiva dos cenários sociais.

Uma escola digna deste nome precisa abrir-se à diversidade, por mais difusos que sejam os dados que manipulamos no cotidiano e justo por isso. Da estrutura social, que nos obriga a trabalhar cada vez mais, sem que tenhamos tempo para criar/amar nossos filhos, ao modo de amor aceito como normal, porque expande o mercado, tudo deve passar pelo crivo de questionamentos e reabordagens, revelando o quanto aí é construção histórica de determinado momento e grupo. Noutras palavras: a escola deve rever a sua política curricular, cujos conteúdos estão ligados a noções hegemônicas, necessitando de superação. ${ }^{3}$ Sobre elas reina ainda com muita força a cultura patriarcal e falocêntrica que impede os alunos de entrar em contato com outras manifestações culturais e estejam assim privados de paradigmas alternativos que não aqueles assentados em nosso circuito contemporâneo.

E leitura é tarefa crucial para efeitos de tal natureza. Leitura que não se desvie para meros formalismos ou desgastantes trabalhos escolares, tendo em vista o que já colocou Denise Escarpit: sendo associada com a realidade escolar, a leitura passa a ser vista como exercício difícil, pouco compensador $^{4}$ e, portanto, estéril. Dentro deste aspecto, na área das atividades de língua, o estudo da gramática pela gramática é o vazio repleto de nada. Muito mais importante é focar a gramática como padrão estabelecido e ir além: decodificar a gramática dos comportamentos, da política, da economia, das histórias oficiais e das paralelas, do vestuário ou da falta dele, da alimentação ou de sua ausência, só para ficar em algumas sugestões. Ler é examinar aquilo que tangencia direta ou indiretamente a vida de cada um de nós. É se perguntar: afinal, por que a vida é e tem sido assim?

3 Com relação à nova política curricular, recomendamos: SILVA, T. T. da. Documentos de identidade: uma introdução às teorias do currículo. Belo Horizonte: Autêntica, 2001.

4 ESCARPIT, apud MELO, J. M. de. Os meios de comunicação de massa e o hábito de leitura. In: BARZOTTO, V. H. Estado de leitura. Campinas: Mercado de Letras/Associação de Leitura do Brasil, 1999. p. 73. 
Leitura encaminhando para o desnudamento do mundo em suas galerias engessadas em posturas centralizadoras, dentro de idéias de normalidade e adequação. $\mathrm{O}$ que quer dizer: de que modo os componentes da casa-grande se esforçam mais e mais para transformar o país em grande senzala, bradando que este é o único rumo certo para a nossa própria estruturação, depois dos desmandos da ditadura militar. Examinar a governança sobre nossos dias é encontrar as farpas de outra ditadura que nos retalha: a do mercado, este transformado em entidade soberana e divina, ao gosto de quem milhares são sacrificados, para que bem se acomodem os interesses de especuladores sem o mínimo senso de humanidade e brilhando na pantomima tida como democracia. Casa-grande que rege o país como uma questão contábil, não nos querendo ver como sociedade. Ler seguindo estas pegadas criaria fulcro revolucionário para as disciplinas de língua e literatura, dentro do que Peter McLaren prega como multicultura-lismo de resistência. ${ }^{5}$

E, ao lidar com leitura, busquemos obras que quebrem os cânones rígidos da legitimação institucional, sensibilizando o aluno para a flutuação dos conceitos. Atentar, na história das artes, para quantos homens e mulheres foram desprezados durante seu tempo de vida, e hoje ocupam o panteão, sendo pacificamente rotulados de gênios, quando é esquecido, de propósito, o seu trabalho com a linguagem que visava, justamente, à ultrapassagem dos limites impostos por sua época. Ninguém faz arte cumprindo regras. Ao romper o estabelecido, ao perguntar por que não pode ser de outra forma, é que o ser humano realiza algo e foge do comum, ficando em condições de receber as benesses do aplauso aprovador. Fazer arte é provocar crise. Ou, como bem coloca Jorge Glusberg:

...não há diferença entre cultura e crise. Cultura é crise, é desassossego, é conflito, é tensão, é troca, é risco, é desorientação, é esperança, é eleição, é princípio de algo. Se não ocorre esta sucessão de incidentes, de contradições, de buscas, de afirmações e negações, não há cultura, não há ciência, não há arte. E, por conseguinte, não há razão nem há liberdade. Há outra coisa: isolamento, talvez genial, há erudição, por acaso fabulosa, há

5 MCLAREN, P. Multiculturalismo e a crítica pós-moderna: por uma pedagogia de resistência e transformação. In: Multiculturalismo crítico. São Paulo: Cortez, 1997. p. 54-104. 
obras, talvez brilhantes, mas não há comunicação, não há realidade, não há sociedade. $^{6}$

Se é troca, risco, desorientação, o que vem fazendo a escola? Um trabalho de abafamento, de silêncio nada obsequioso em que a dimensão humana do aluno é tratada como peça não bem esculpida ainda, mas já encaixotada nas prateleiras do senso comum. E o aluno vê-se preso a conceitos de disciplina e de aprendizagem que evitam em especial a sucessão de incidentes e contradições. Não por acaso, cada matéria tem um programa definido em objetivos e etapas, elaborado a priori pelo professor ou equipe pedagógica, sem se ouvir a voz do aluno, no interesse de suas reais necessidades antes referidas.

A sala de aula, transformando-se em palco de interação com os mais variados discursos - gibi, cinema, teatro, dança, culinária, sexualidades, jornal, etnias, moda, TV, esportes, movimentos sociais etc. - teria como contrapor estas vozes aos espaços silenciados impostos pelo livro didático. O ser humano, em sua amplitude confusional, estaria historicizado, em nome do que transporíamos as mistificações da imanência. Estamos enfatizando: um texto (qualquer texto) por si só não teria status de ser grandioso ou não, tudo a depender das formulações que se criam em torno dele, a partir dele. O texto, tratado desta forma, seria apenas a ponta do iceberg para o jovem perceber-se igualmente como ser em construção e não alguém já pronto por desígnio dos deuses. Veria, assim, que sua "subjetividade não é dada, mas produzida, constituindo, portanto", também um "objeto de análise e não" seria a certa "premissa ou seu ponto de partida".? E, por este meio, mergulharia de corpo inteiro naquele "olhar interdisciplinar que entende os processos culturais como interdependentes e não como um fenômeno isolado", sendo que tal interdependência caracteriza "uma relação dinâmica com outras esferas, principalmente com a estrutura ou os

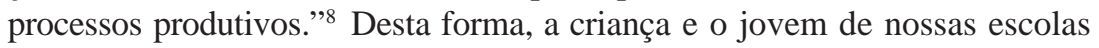

6 MORAIS, F. Arte é o que eu e você chamamos arte: 801 definições sobre arte e o sistema da arte. Rio de Janeiro: Record, 1998. p. 176.

7 JOHNSON, R. O que é, afinal, Estudos Culturais? Trad. e org.: Tomaz T. da Silva. Belo Horizonte: Autêntica, 2000. p. 27.

8 ESCOSTEGUY, A. C. D. Cartografias dos estudos culturais: uma versão latinoamericana. Belo Horizonte: Autêntica, 2001. p. 43. 
estariam em condições de aprender-se como ser em relação e não como mônada isolada dos demais, dando braçadas nas águas desgastantes do individualismo. Águas essas que levam a praias desertas, a ilhas sem intercomunicação, ao narcisismo doentio cujo resultado conhecemos bem: basta ver o mundo em que vivemos, pronto a prestigiar o sucesso pessoal como dom, sem considerar o trabalho que há por trás e, em especial, o número de deslocados que foram sendo triturados ao longo das engrenagens do prestígio e, depois, jogados à margem.

Desde as primeiras letras, é recomendável que o aluno aprenda que as classificações são da ordem do discurso, portanto, modificáveis, em estreita ligação com o sujeito que fala, da posição que fala, mais do que como resultado do objeto focado. E isto não é trivializar a sagrada aura da arte, pois esta nada tem de sagrado, e sua aura há muito foi decantada pelas próprias rupturas que fazemos constantemente na tradição, pelo deslocamento da idéia de cultura e de arte do circuito estreito da reprodução "para o campo dos processos constitutivos e transformadores do social". 9 Isso tem o saudável resultado de tirar o aluno de frente das falsas seriedades do mundo, segundo a saborosa perspectiva irônica de Claudio Magris: "o sentido da pequenez de tudo o que é finito (...) com relação ao grande pano de fundo do infinito, diante do qual se coloca toda a experiência humana. Esse sentimento permite não se levar demasiado a sério, e liberta, portanto, dos venenos da insegurança e da soberba, mas também permite não levar a sério nenhuma pretensa grandeza e liberta, portanto, do medo". ${ }^{10} \mathrm{O}$ caminho entre o aluno e o livro não será assim recamado por crendices e superstições danosas do tipo fulano escreve porque é dotado de genialidade inata. E em cada livro lido terá ele uma sugestão do que pode fazer em termos de elaborar a vida longe do tédio, da falta de perspectiva, da estreita sensação de que viver é apenas sobreviver a duras penas.

Linguagem (artística, científica, jornalística etc.) é trabalho, fruto de uma série de variantes que cabe ao professor analisar no momento de fazer a necessária mediação entre o livro e seus leitores. De nada têm valido os pedestais em que são entronizados nossos autores. Sabemos que toda estátua serve para guardar a pátina do tempo e ser morada de pássaros viajores. Ou então, para assustar desavisados passantes. Livros são escritos pelo desejo de se compartilhar algo com alguém, não para se criar um fosso entre o autor e o mundo. Aliás, a diversidade de livros e estilos, de temas e

9 ESCOSTEGUY, op. cit, p. 47.

10 MAGRIS, C. Microcosmos. Rio de Janeiro: Rocco, 2002. p. 122. 
abordagens, de linhas e conclusões deixa por terra o idealismo funesto de querer cercar de grandeza mítica aqueles que os escreveram. Estes, salvo prova em contrário, pertencem à humanidade e, como trabalham a palavra e sua relação com os escaninhos do mundo, chegam ao resultado que conhecemos. Nosso jovem leitor aprenderá com eles a ser também um autor e descobrirá um modo de participar do concerto em aberto das realidades que nos são compatíveis. Portanto, ler tem os pés fincados no aprendizado da real democracia: estamos aqui para ser modeladores de nossa história e não apenas consumidores da alheia. É, por este viés, necessário que o livro entre na sala de aula como obra de mulheres e homens que vivem dadas circunstâncias histórico-sociais, talvez muito próximas daquelas dos alunos, talvez distantes, o que contribuirá para a ampliação das esferas vivenciais destes. O autor, a autora são movidos por angústias, ansiedades, atrevimentos, alegrias como qualquer outro. Lembremos: "a função da arte em relação à sociedade é expressar, a qualquer preço, o que está atrás do muro. O artista é o que arranca o véu. Toda linguagem é violação. Violação de regras". ${ }^{11}$

O muro é o mundo. Acima, atrás, na frente, dentro, embaixo estamos todos nós. Violando os véus do templo e do tempo que se revelam simples efeito especial de piroctenias culturais, aprendemos a nos localizar, a transformar o próprio espaço e não é fortuito que muro passou a ser metáfora de opressão. Cada livro é busca de resposta. É célebre o fato de Hemingway procurar soluções para seus entraves nas obras que lia. Não as encontrando, resolveu, por sua vez, escrever. Levando-se em conta seu fim trágico, podemos supor que não as encontrou. Ainda bem, pois nesta caminhada, deixou-nos uma série de obras-primas capazes de justificar e recriar a vida, cercando-a de tempero especial. A leitura, como estímulo a descobertas e a autodescobertas, fermenta de tal maneira o cotidiano do leitor aprendiz ou do leitor contumaz que, cedo ou tarde, sua mente, alimentada pela babel de discursos, haverá também de florescer com o seu próprio e um palmo do universo será menos árido. Ao mesmo tempo, teremos dado importante passo na consolidação dos direitos, em especial do direito e da coragem de criar:

11 MORAIS, op. cit., p. 174. 
...a coragem criativa é a descoberta de novas formas, novos símbolos, novos padrões segundo os quais uma nova sociedade pode ser construída. Toda profissão pode exigir e exige coragem criativa. Nos nossos dias, a tecnologia e a engenharia, a diplomacia, o comércio, e sem dúvida o magistério, todas essas profissões, e dezenas de outras, passam por mudanças radicais e precisam de indivíduos corajosos que valorizem e dirijam essas mudanças. A necessidade de coragem criativa é proporcional ao grau de mudança. ${ }^{12}$

Se não bastasse isso, procuremos recordar as investigações de Vigotsky, para quem a atividade de criar está embasada nas relações sociais, já que nestas se encontra a vivificação das linguagens, sendo a atividade criadora do homem não a exceção, mas a regra. Ler é aprender este fato tão simples e tão demolidor de mitos que, derrubados, deslocam o eixo do mundo, dando ar para que todos respiremos livres de cangas a atrapalhar o crescimento.

\section{Cena 3: A arte como the dark side}

Em recente entrevista à Folha de São Paulo, Carlos H. Cony diz: "você acha que alguém feliz faria a Nona Sinfonia? Um homem feliz faria as pinturas de Goya?" e complementa a idéia ao afirmar que, "quando estava muito bem", tendo feito o livro que queria, deixou de escrever. Mas, "depois, uma série de fatores me fizeram me descobrir desamparado", o que motivou seu retorno à literatura. ${ }^{13}$ Disto podemos inferir que a literatura, como qualquer arte, é fruto da angústia do indivíduo em sua relação com o mundo (entre outros fatores, claro). Diante da escuridão do nãosentido, o homem procura um sentido. Este, certamente, é o mecanismo primeiro que o leva à leitura, no encalço de respostas, na tentativa de en-

12 MAY, R. A coragem de criar. Rio de Janeiro: Nova Fronteira, 1982. p. 19.

13 MACHADO, C. E. O balanço de Cony: escritor prepara "Missa para o Papa Marcello", sua última ficção. Folha de São Paulo, 2 fev. 2002. Ilustrada, p. E-1 e E-3. Entrevista. 
contrar perfil mais ou menos definido em meio à imensa nebulosa que chamamos de vida. Ora, nossa sociedade frenética, acostumada a vender a felicidade fácil por meio do consumo, não oferece mais espaço para este tipo de questionamento. Ao lado do consumo, da terapia enganosa dos livros de auto-ajuda, da tecnologia famacopéica com suas pílulas que revestem a mente com espécie de capa de silicone para acolchoar os embates com o mundo, tenta oferecer-nos proteção frente às tempestades relacionais. A angústia passou a ser mal vista, logo, indesejada. Tratando-a como um mal em si mesma, não se aprende a ver nela um processo possível de descobertas, criação, mudança a nos levar a um passo além do limite. Dos jovens intoxicados pelo charivari de boates e shoppings a adultos anestesiados pelo ritmo de trabalho no qual não temos condições de mergulho interior, vivemos as crises como maléficas, não como reconversão do olhar. Nisto, estamos perdendo chance de ouro de cavoucar nas superfícies e nos modelos absorvidos para adentrar portas de labirintos que nos transportem a reposicionamentos vários. A homogeneização de nossa sociedade, das roupas ao discurso, das idéias de conforto ao prazer, conduz a esmagadora maioria a seguir a mecanização da vida que passa a ser encarada como esforço brutal de nos encaixar em nichos prontos, sem que nos lembremos de que são descartáveis - amanhã, com urgência, precisaremos de outros e outros e, assim, reeditamos o mito de Procusto.

Pensando que crise é essencialmente mudança de perspectiva e, como a sociedade, por todos os meios, projeta para o indivíduo um modus vivendi em que ela é banida ou sufocada, cabe-nos afirmar que nosso olhar estará cravado sempre no mesmo ponto: nos ícones da TV, do cinema, do esporte, daquela galeria de vitoriosos que, vicariamente, vivem em nosso lugar a experiência benjaminiana que já não podemos ter. Não é de admirar, então, que o número de leitores decresce, que o livro se ausente de nossas vidas. Fardados dentro da estandartização da vida como modelo criado pela indústria do lazer, rejeitamos o livro. Claro, este não traz resposta, nem massageia nossa dor tópica. Pelo contrário, nele se desdobram infinitas perguntas que ocuparão todo um viver como processo de análise das linguagens, quando então se descobre meio de criar/modelar a própria linguagem, na imersão de outras, e sem a certeza fixa de estarmos no centro do mundo.

Na política de terra arrasada, própria de nossa sociedade, não interessa mais problematizar o que quer que seja. Interessa apenas adaptar-se rapidamente ao que está pronto e tido como exemplar. Neste padrão, não só a leitura não é praticada, porque incomoda, tira-nos da platitude cotidia- 
na, como o livro é descartado como objeto dispensável, sobretudo, como corpo estranho, por inquirir e trazer fissuras e manchas no painel luminoso da rotina recheada de felicidade prêt-à-porter. O corpo em movimento é a ordem do dia, o modelo de ser sarado obceca jovens e mais maduros, estes resistindo ao próprio envelhecimento que se tornou vergonhoso numa comunidade que prega a eterna juventude. Mesmo que a agitação não leve a lugar nenhum, ela comanda, em especial nos grandes centros, as agendas. Vista de outro modo, esta agitação leva, sim, a um ponto: estão aí as comarcas do individualismo, os estados de violência, as fugas pelas drogas, a banalização da vida e da morte, substitutos do não-sentido que teimamos em não ver como instigação à procura. E tudo isso acaba afunilando-se para estimulações nervosas de agrupamentos humanos untados de sugestões de frenesi em que se perde a causa do grande vazio, confundido com a própria conseqüência de estarmos uma vez mais num novo dandismo de pletoras improdutivas. Tais agrupamentos desviaram-se da perspectiva do social, cada um se encarregando das próprias feridas como inscrições pessoais. Abolem a pergunta, abortam a tentativa de diferentes configurações para o estar no mundo e sua dinâmica de contatos. $\mathrm{O}$ virtual substituindo o real não é desígnio dos deuses. Outra vez, tudo o que cheira à arte, a pensamento, à vida mental é rotulado como fora do esquadro, passadismo. Nesta sequiência, a vertigem do pós-humano ${ }^{14}$ se faz presente em nossas casas e ruas, quando vamos automatizando-nos, ressecados da seiva convivente que dá substância ao ser em estado de consciência, como ciência com o outro. Além disso, somos espécie pós-moderna de selvagens enrustidos em seu matagal de signos, no qual não tem penetração nada que não esteja previsto pelos mandamentos mercadológicos - pó instantâneo a ser diluído na água da superficialidade aerodinâmica, virtual, analógicodigital. Ler para quê? Não podemos perder tempo. A desorientação empurra-nos ao dinheiro, e ler/pensar não gera este pomo divino da falsa esperança.

Tendo isto em mira, com os possíveis exageros de nossa abordagem, para a leitura ter abrigo na vida das pessoas é urgente redimensionar os próprios modelos de existência, isto é, rever aquilo que até há pouco tempo se chamava filosofia de vida, com perdão pelo anacronismo. Distanciados de um remodelamento das bases de nosso cotidiano, caímos no que ficou

14 Sobre a noção do pós-humano, cf. HARAWAY, D.; KUNZRU, H.; SILVA, T. T. da (Org.). Antropologia do ciborgue: as vertigens do pós-humano. Belo Horizonte: Autêntica, 2000 . 
bem explicitado por Frei Betto: "falávamos em produção. Hoje falamos em especulação. O mundo virou um cassino global (...), em que dinheiro rende dinheiro. Há mais dinheiro virtual do que real. Falávamos de trabalho; o trabalho era, na modernidade, o fator de identificação do ser humano. Hoje, fala-se no mercado, quem está e quem não está no mercado". ${ }^{15}$ A arte, feita sob os impulsos da necessidade de se encontrar um significado para o cada um de nós estar em relação discorde com o outro, elabora-se no confronto dialético de discursos, evidenciando por si só a imensa pluralidade de nossas contradições, o poliedro desconexo de nossas peregrinações. Retomemos o pensamento de Jean Galard: "numa sociedade bem organizada, submetida aos interesses de quem deseja ver conservar-se a ordem das coisas, não temos senão dois modos de explorar nossos limites mais distantes: a arte e o crime". ${ }^{16} \mathrm{O}$ macabro festival das manchetes de jornais a nos martelar cada manhã ou cada noite não seria ilustração convincente desta falta de saída? O homo sapiens, castrando o aprendizado do faber e do ludens sob a ordem de coisas estereotipadas, não está assimilando o crime por isto? Na obra de Sade encontramos pungente alerta a respeito.

Longe da arte, com o livro abolido de nossas vidas, vamos substituí-lo por quinquilharias entropicamente fadadas a desaparecer ao primeiro toque, quando não muito, porque parece que as pessoas estão aceitando que viver é isto mesmo: ter um emprego (não trabalhar), receber salário, pagar contas. E não é apenas uma questão de revirar valores e sim de alterar a rota de práticas instituídas por estes valores e de valores que brotam destas práticas, num mundo em que fica demonstrado a cada dia menos percepção desses processos. O trabalho de consciência e despertar a se fazer é árduo, em especial porque a tecnologia, em suas diversas frentes, que tem tudo para ser nossa aliada na democratização do saber, do saber-se com o outro, nos está isolando, à medida que nos encastelamos nos nichos mencionados, onde temos a impressão de que o eu consigo próprio se basta: "formas comunicativas instantâneas e interdependentes que, com seu operar, contribuem a fazer com que a fisicidade e a substancialidade dos contatos cotidianos se percam no interior de mundos artificiais nos quais os indivíduos se comunicam entre si mesmos, utilizando instrumentos eletrônicos de forma crescente". ${ }^{17} \mathrm{O}$

15 LIBÂNIO, op. cit., p. 14-15.

16 MORAIS, op. cit., p. 177.

17 SIBOLDI, G.; SALVO, M. di. A evolução da informática e as relações afetivas do indivíduo. In: PELUSO, A. (Org.). Informática e afetividade: a evolução tecnológica condicionará nossos sentimentos? Bauru: Edusc, 1998. p. 13. 
outro é afastado, substituído pelo intercâmbio de mensagens na tela de nossos visores, e a vida, na modalidade da interação material sociodivergente, se esboroa. $\mathrm{O}$ ciborgue que tem como premissa ampliar as condições desta mesma vida transforma-se em narciso crônico, eterno adolescente a imaginar-se auto-suficiente, desligando-se de necessidades de negociação política e diálogo com o outro.

\section{Cena 4: Uma pequena heresia}

Levando em conta as questões que apresentamos acima e os avanços dos Estudos Culturais, talvez não fosse exagero afirmar que a arte $\mathrm{em} \mathrm{si}$ não existe. $\mathrm{O}$ que existem são abordagens discursivas que dão nobreza, destaque, fortuna crítica a determinados produtos, enquanto outros são marginalizados ou ignorados. Para ficarmos num exemplo: nos anos 70, quando cursamos Letras nesta universidade, Lima Barreto era lido como autor menor. O principal anátema: não soube distinguir literatura de jornalismo. Hoje, ele foi guindado à altura do cânone, como um de nossos mais importantes escritores. O que mudou? Sem dúvida, nosso olhar, nossa sensibilidade a respeito de sua obra, para os quais contribuiu, com certeza, a leitura de Osman Lins, ao escrever Lima Barreto e o espaço romanesco, ${ }^{18}$ resgatando do limbo alguém praticamente esquecido. E agora, com a tradição bakhtiniana criada entre nós, justo os passeios daquele autor entre o jornalismo e a literatura nos interessam e garantem seu status de bom escritor. Por aí se vê que o literário não depende de imanências textuais. ${ }^{19}$ Ler dentro deste espírito é liberalizador e carnavaliza as impostações do mundo e suas hierarquias convencionais, com seu desfile de pompas ocas, esquecidas dos pés de barro. Não é novidade que somos pó. Falta abrir olhos e mentes para enxergar o pó de nossas obras. Ou, conforme diz Cees Nooteboom, ao refletir sobre sua paixão pelos clássicos e encontrar neles antídoto contra a ânsia de fama e reconhecimento que consome muitos de seus colegas escritores: "toda vez que estou preocupado, leio Ovídio,

18 LINS, O. Lima Barreto e o espaço romanesco. São Paulo: Ática, 1976.

19 A respeito desta questão, cf. VENTURELLI, P. Leitura: paixão do conhecimento. Letras, Curitiba, n. 44, p. 175-184, 1995. 
Homero, Platão, Cícero e me pergunto quem na minha geração será lido daqui a dois mil anos. O que Virgílio teria pensado se ele tivesse visto um exemplar da Eneida numa livraria do Rio de Janeiro em 1995?"20

Antes de o pó desfazer-se, ele pode ser modelado com nossas mãos, tornando a vida mais lúdica, menos insignificante e uma atitude prática longe do circo de horrores a que estamos sujeitos quanto mais decaem as grandes fraudes econômicas de nossos tempos. A arte como processo de descoberta e criação, para o qual não há regras estabelecidas, liberta o homem da nulidade da mera submissão a legitimações acadêmicas que são insufladas pela sociedade como verdades intocáveis. É mais ou menos isso que lemos em Paulo Freire: "eu acho que à leitura autoritária, se a nossa opção é libertária, temos que propor a leitura libertária, que é uma leitura da coragem de não entender o que se leu, que é a leitura do correr risco porque (...) eu não corro risco só porque eu escrevo, eu corro risco também quando leio, porque ler é reescrever". ${ }^{21}$ É nesta área de risco, de atrevimento que devemos investir nossos esforços, o que implica a alfabetização cultural a que se refere Eliana Yunes, para quem "só vai gostar de literatura quem tiver uma experiência de literatura libertária e não a experiência de censura, castradora, restritiva e redutora." 22 Não por acaso, a palavra liberdade e seus correlatos aparecem diversas vezes em nosso escrito. Criar/ler/escrever, uma rede de interações que pressupõe o estado do homem livre ou o exige. E liberdade espraia-se para a superação daquele tipo de analfabetismo rotulado por S. Jerônimo como "a ignorância desejada", ou seja, "a atitude de quem, deliberadamente, não dá importância à cultura, mesmo tendo um grau satisfatório de escolaridade". ${ }^{23}$ E aqui entramos noutro campo escorregadio: que importância tem a literatura na sociedade atual? "Somos a última geração literária da humanidade", enfatiza Frei Betto. ${ }^{24}$ "No século XX, a literatura é definitivamente apreendida como um meio de comunicação esotérico", brada Hans Gumbrecht. ${ }^{25}$ Ao aceitar-

20 NOOTEBOOM, C. Jornal do Brasil, 9 dez. 1995. Idéias. (Notas de arquivo, sem referências bibliográficas).

21 FREIRE, P. Da leitura do mundo à leitura da palavra. In: BARZOTTO, op. cit., p. 29. Entrevista concedida a Ezequiel T. da Silva.

22 YUNES, E. Além do domínio do alfabeto. Gazeta do Povo, Curitiba, 18 nov. 2001. Caderno G, p. 7. Entrevista.

23 MANGUEL, A. Ler é poder. Veja, p. 15, 7 jul. 1999. Entrevista.

24 LIBÂNIO, op. cit., p. 15.

25 GUMBRECHT, H. U. Modernização dos sentidos. São Paulo: Editora 34, 1998. p. 317 . 
mos tais posturas, não estamos levando em conta o público em geral, nem a abstração chamada povo. Pensamos em nosso meio: o curso de Letras, de Artes, o magistério fundamental e médio em que trabalhamos. Ali, literatura é língua estrangeira. Se somarmos todos os estudantes dessas áreas, mais os professores, certamente ultrapassamos a cifra de alguns milhões. Qual a tiragem média de livros das editoras brasileiras? Até há pouco tempo, três mil exemplares, número em decréscimo. O que isto significa? Nem os profissionais, nem os que se preparam para a carreira estão lendo, ou o fazem de forma inexpressiva, se levarmos em conta a performance em sala de aula dos alunos ou dos professores durante cursos que nos são solicitados. Essas histórias de vida estão travadas por trauma que se chama leitura na escola. Como "parte da maravilha e da riqueza da leitura vem da liberdade que ela sugere e da possibilidade de vagar por florestas e prateleiras, escolhendo o livro certo para aquele momento", ${ }^{26}$ a obrigatoriedade mensal ou bimestral de leitura vem podando gerações que são impedidas desta fruição, carregando na mente o ônus de ver o livro ou a biblioteca como espaços de castigo. É preciso mudar a direção, o sentido e o conteúdo desta prática nefanda. Em nossa visão, o foco distorce antecipadamente qualquer resultado que é perseguido pela leitura na escola. A crítica cultural vem pondo em cheque a indefinível literariedade. Mesmo porque, o que é literatura? Cada vez mais, os espaços fronteiriços das produções de texto estão sendo diluídos, em especial com a noção dialógica e intertextual presente. Tal postura corrói a configuração da instituição que se tornou tradicional, quando a literatura passou a ser analisada como um produto autônomo, vinculado à essência da genialidade inspirada de autores. Como se estes levitassem a quilômetros da Terra, sem contato com a materialidade da vida. Em conseqüência, por que insistir numa pretensa literariedade de certos textos e impingi-los como legítimos? Como escreve Aldo Bizzocchi:

...se o objeto do ensino de literatura na escola média é estimular no aluno o hábito da leitura, então, por que, em vez de obrigá-lo a ler obras de ficção de séculos passados, não se propõe a ele a leitura de obras importantes de não-ficção da atualidade, como os livros de Sérgio Buarque de Hollanda e Milton Santos, por sinal muito bem escritos, ou os de Carl Sagan, que possuem aliás, excelentes traduções em português? ${ }^{27}$

26 MANGUEL, op. cit., p. 15.

27 BIZZOCCHI, A. Repensando o ensino de literatura. Folha de São Paulo, 10 jul. 
Está assim materializado o $X$ da questão. Chegou a hora de mudarmos de rota. Sendo nós a última geração formada à sombra luminosa da literatura, sendo esta puro esoterismo para os que estão chegando, precisamos ter coragem de abandoná-la por uns tempos. Enfatizemos: como o literário não se enquadra em nenhum a priori e sua natureza se ressalta da tessitura com outras linguagens, é com estas outras linguagens que a escola trabalharia. Está na hora desta abrir-se para a narrativa das mulheres, dos negros, das sexualidades segregadas, dos índios, das ciências, dos esportes, das ideologias etc. etc., na trilha dos Estudos Culturais que

...questionam a produção de hierarquias sociais e políticas a partir de oposições entre tradição e inovação, entre a grande arte e as culturas populares, ou, então, entre níveis de cultura - por exemplo, alta e baixa, cultura de elite e cultura de massa. A consequiência natural desse debate é a revisão de cânones estéticos ou mesmo de identidades regionais e nacionais que se apresentam como universais ao negarem ou encobrirem determinações de raça, gênero e classe. ${ }^{28}$

Só depois de bem sensibilizado sobre esta questão basilar - a sociedade como arena de discursos desarmônicos - é que o aluno terá condições de se defrontar com o literário como um passeio criativo entre tais discursos. Estamos malhando em ferro frio, esquecidos de que arte e literatura foram banidas das vidas das pessoas que, sequer, têm consciência delas, na maioria dos casos. Para retornar ao professor Aldo Bizzocchi: "no nosso entender, o conhecimento de literatura não é mais importante do que o de outras formas de manifestação artística nem deveria ser privilegiado em detrimento das demais artes." 29

2000. p. A-3. Acrescentamos à sugestão do autor as obras de Stephen Jay Gould, Richard Dawkins, Alan Lightman, Freman Dyson, Russel Martin, Marcelo Gleiser que, além de livros, têm seus artigos estimulantes publicados semanalmente no caderno Mais! da Folha de São Paulo; Rogério Cerqueira Leite, a coleção "Baderna", da Editora Conrad, que focaliza as novas formas de organização e luta contra os desmandos do capital, a revista Galileu e dezenas de outras publicações que trazem o mundo escrito e são excelentes condutos para preencher o espaço estéril de tantas salas de aula.

28 ESCOSTEGUY, op. cit., p. 41.

29 BIZZOCCHI, op. cit., p. 3. 
Numa época como a nossa, sacudida a todo instante pelas vozes das ciências, das tecnologias, das lutas sociais, é premente ouvir essas vozes e decompô-las, acompanhando suas trajetórias. Cada gesto social destes é uma narrativa e, trabalhar com ela é auxiliar o aluno a entrar em seu próprio mundo e entendê-lo um pouco mais. Como "a dimensão de uma obra depende também da experiência pessoal de cada um, de quanto sua vida foi transformada por ela", ${ }^{30}$ o aluno bem enfronhado com esta natureza de narrativas terá experiência de transformação suculenta a lhe dar asas para vôos literários. Interagindo com os produtos históricos do seu tempo, por mais indistintos que pareçam, esta mente jovem tornar-se-á campo aberto para diálogos ininterruptos com as facetas poliédricas e em rede de sua vida mesclada a outras vidas. Alcançará diapasão adequado para medir seu próprio viver em confronto direto ou indireto com o outro, confronto que, se humanizado, torna-se diálogo, abertura ao diferente, compreensão da multifacetação de cada campo social, interesse em ouvir e colaborar. O dimensionamento do artístico depende desta arquitetura mental entrelaçada com a experiência e com o filtro da experiência de outras vivências, com as quais o aluno comporá sua vida e sua história de leitura como ato verdadeiramente libertador.

Um homem bem formado no embaralhamento polifônico da sociedade chegará à conclusão de que "se eu mesmo sou um ser acabado e se o acontecimento é algo acabado, não posso nem viver nem agir: para viver, devo estar inacabado, aberto para mim mesmo - pelo menos no que constitui o essencial da minha vida -, devo ser para mim mesmo um valor ainda por vir, devo não coincidir com a minha própria atualidade." 31 Quem sabe, ver-se por este prisma seja angustiante. Angústia da natureza daquela apontada na fala de Cony: propulsão para criar, impulsão para encontrar resposta, arrojo para ir além do conhecido. Neste caminho, como o Montag, de Bradbury, em lugar de atearmos fogo aos livros, seremos convertidos (e esta é a palavra: conversão, sedução) pelos seus desafios, haveremos de amá-los como um modo de vida, já que "ler nos conduz à alteridade, seja à nossa própria ou à de nossos amigos, presentes ou futuros. Literatura de ficção é alteridade e, portanto, alivia a solidão." ${ }^{32}$ Aliviados em nossa soli-

30 MANGUEL, op. cit., p. 14.

31 BAKHTIN, M. Estética da criação verbal. São Paulo: Martins Fontes, 1992. p. 33.

32 BLOOM, H. Como e porque ler. Rio de Janeiro: Objetiva, 2001. p. 15. 
dão, saberemos como nos entrosar com a cultura na modalidade de respiradouro e não esmagamento e, dentro de tal quadrante, Guernica não nos causará silêncio constrangido e, sim, estímulos para sairmos do rés do chão e, via leitura, recriarmos a vida como possibilidade inventada a cada dia.

\section{REFERÊNCIAS}

BAKHTIN, M. Estética da criação verbal. São Paulo: Martins Fontes, 1992.

BARZOTTO, V. H. (Org.). Estado de leitura. Campinas: Mercado de Letras/Associação de Leitura do Brasil, 1999.

BIZZOCCHI, A. Repensando o ensino de literatura. Folha de São Paulo, 10 jul. 2000. p. A-3.

BLOOM, H. Como e por que ler. Rio de Janeiro: Objetiva, 2001.

BRASILEIRO não encontra prazer na leitura. Folha de São Paulo, 14 jul. 2001. Ilustrada, p. E-8.

CONY, C. H. O balanço de Cony. Folha de São Paulo, 2 fev. 2002. Ilustrada, p. E-1 e E2. Entrevista concedida a Cassiano E. Machado.

ESCOSTEGUY, A. C. Cartografias dos estudos culturais: uma versão latino-americana. Belo Horizonte: Autêntica, 2001.

GUMBRECHT, H. U. Modernização dos sentidos. São Paulo: Editora 34, 1998.

JOHNSON, R.; ESCOSTEGUY, A. C.; SCHULMAN, N. O que é, afinal, Estudos Culturais. Trad. e org. Tomaz T. da Silva. Belo Horizonte: Autêntica, 2000.

LIBÂNIO, C. A. (Frei Betto). Um sentido para a vida. Revista de Educação, Salvador, n. 27, p.7-19, dez. 1999. CEAP.

MAGRIS, C. Microcosmos. Rio de Janeiro: Rocco, 2002.

MANGUEL, A. Ler é poder. Veja, São Paulo, p. 11-15, 7 jul. 1999. Entrevista a Tania Menaí.

MAY, R. A coragem de criar. Rio de Janeiro: Nova Fronteira, 1982.

MCLAREN, P. Multiculturalismo crítico. São Paulo: Cortez, 1997. 
MORAIS, F. Arte é o que eu e você chamamos arte: 801 definições sobre arte e o sistema da arte. Rio de Janeiro: Record, 1998.

PELUSO, A. (Org.). Informática e afetividade: a evolução tecnológica condicionará nossos sentimentos? Bauru: Edusc, 1998.

SILVA, T. T.; HARAWAY, D.; KUNZRU, H. (Org.). Antropologia do ciborgue: as vertigens do pós-humano. Belo Horizonte: Autêntica, 2000.

. Documentos de identidade: uma introdução às teorias do currículo. Belo Horizonte: Autêntica, 2001.

VENTURELLI, P. Leitura: paixão do conhecimento. Revista Letras, Curitiba, n. 44, p. 175-184, 1995.

YUNES, E. Além do domínio do alfabeto. Gazeta do Povo, Curitiba, 18 nov. 2001. Caderno G, p. 7.

Texto recebido em 22 jul. 2002 Texto aprovado em 26 ago. 2002 